\title{
The role of schools' perceived human resource policies in teachers' professional development activities: a comparative study of innovations toward competence-based education
}

\author{
Audrey Seezink $\cdot$ Rob Poell
}

Received: 3 April 2009/Revised: 9 July 2010/Accepted: 27 July 2010/Published online: 4 November 2010

(C) The Author(s) 2010. This article is published with open access at Springerlink.com

\begin{abstract}
The change toward competence-based education has implications for teachers as well as school management. This study investigates which professional development activities teachers undertake related to this change and how these activities differ among schools with various human resource (HR) policies. Two types of HR policy were involved: (1) a government-enforced, national system of Integrated Personnel Management and (2) a voluntary, integrative approach of Schooling of teachers, Organizational development of schools and teacher training institutes, Action- and development-oriented research, and Professional development of teachers. Semi-structured interviews with 30 teachers in nine schools with different HR policies were held and analyzed both qualitatively and quantitatively. Findings show that teachers undertake professional development activities in five categories: maintaining knowledge base, applying and experimenting, reflection, collaboration, and activities indirectly related to teaching practice. Teachers' professional development activities were found to be relatively similar across schools with different HR policies. It is concluded that neither government-enforced nor voluntary HR policies seem to play much of a role in the participation by teachers in professional development activities. Implications for further research and school practice are discussed.
\end{abstract}

Electronic supplementary material The online version of this article (doi:10.1007/s12564-010-9115-z) contains supplementary material, which is available to authorized users.

\footnotetext{
A. Seezink $(\bowtie) \cdot$ R. Poell

Department of Human Resource Studies, Tilburg University, PO Box 90153, 5000, LE, Tilburg, The Netherlands

e-mail: Audrey.Seezink@gmail.com

R. Poell

e-mail: R.Poell@uvt.nl
}

Keywords Continuing Teacher Development . Professional Development · Human Resource Policies · Competence-Based Vocational Education

Competence-based education has acquired a firm foundation in European countries (Weigel et al. 2007). The need for competence-based education is related to a perceived gap between what is learned in schools and the demands of the work society (Biemans et al. 2004). This was especially apparent in the context of pre-vocational secondary education in the Netherlands, which is the setting for the present study. At age 4, Dutch pupils enroll in general primary education. After completing this at age 12, they can pursue their educational careers in three ways: (1) a 4-year pre-vocational secondary education program (PVSE, in Dutch: VMBO) (2) a 5-year senior general secondary education program (SGSE, in Dutch: HAVO), and (3) a 6-year pre-university education program (PUE, in Dutch: VWO). Approximately $60 \%$ of all pupils attend PVSE, which forms the specific context for the present study (Seezink and Poell 2010).

PVSE prepares pupils for an entry into senior secondary vocational education (SSVE) where they obtain a vocational qualification and, eventually, for careers in various vocational contexts (educating them for various vocational occupations as hair dressing, carpentry, construction, and so forth) (Seezink and Poell 2010). In order to better prepare pupils for SSVE and their further careers, PVSE schools in the Netherlands have been innovating their educational programs for pupils so as to establish stronger links among the demands of society, work organizations, and vocational education; competence-based education is deemed capable of doing this (De Bruijn 2004; Mulder 2002). Although some have pointed out that competence-based 
education carries with it the risk of 'tick-box' behavior (e.g., Tomlinson 1995), Dutch scholars generally prefer to emphasize that pupils are becoming more responsible for organizing their own learning processes (De Bruijn et al. 2005; Van der Sanden 2004; Van Velzen 2002).

It is often assumed that the implementation of competence-based education for pupils implies that teachers can no longer adhere to their former roles within a knowledge transmission model and that, hence, they need to change their teaching practices toward knowledge construction (Vermunt and Verschaffel 2000). Teachers are, for instance, expected by their schools to find new ways of customizing educational arrangements to pupils' occupational careers. In order to succeed in this, teachers are expected by their schools to undertake various professional development activities (Seezink et al. 2009).

Besides the continual changes within educational practice, however, there are other reasons why teachers may be expected to engage in professional development activities. First, some countries have a regulatory system in which engaging in CPD activities is mandatory (Watkins 1999). Second, employee development can also be driven partially by a need for employee mobility (Blau et al. 2008). Motives for continuing professional development can be described as inward focused (e.g., aiding one's co-workers and improving practice within the organization) or outward focused (e.g., improving or supporting one's own occupation or profession) (Blau et al. 2008).

\section{Teachers' professional development activities}

There is a general consensus that learning to teach is a lifelong process (e.g., Atay 2008; Clandinin 2008; Lohman 2006). The term 'professional development', however, has many interpretations and definitions. Bergen and Van Veen (2004), for example, state that professional development of teachers can be characterized as warranting future suitability of individual teachers regarding the practice of their profession. Van Driel (2006) also views professional development as a way of learning on the job over time; however, he stresses the importance of an organized method. The definition used in the present study is derived from Kallenberg (2004) and focuses on the development and improvement in professional behavior in work-related situations related to daily teaching practice. Kwakman (1999, 2003b) distinguishes among four categories of professional development activities, the first three of which are individual in nature: reading, experimenting, and reflection. Reading is aimed at acquiring new knowledge and skills. Experimenting is the application of new developments and insights to teaching practice. Reflection aims at the evaluation of their teaching performance.
Collaboration was added as a fourth category because, although individual learning can be very helpful, teachers often point out that they learn a lot from the interaction with others (Kwakman 1999, 2003a). Although the generalizability of Kwakman's categorization to other educational contexts (e.g., PVSE) is not entirely clear, it offers a useful starting point to frame teachers' professional development activities.

\section{Schools' human resource policies}

The change toward competence-based education has implications not only for teachers but also for school management. In former times, school management in the Dutch educational system was not concerned with teaching practice but rather focused on managerial and organizational aspects only. As Van Driel (2006) has noted, this resulted in a clear separation between teaching practice and management practice. Also, personnel management within secondary schools was an underdeveloped area. Often, this was restricted to recruiting new teaching staff, and managing teachers' professional development gained little attention (Van Driel 2006). This has changed as a result of two developments in the human resource (HR) policies of schools, which will be elaborated upon below. Although most schools are still far from systematically using HR policies to further their strategic goals (Scribner et al. 2008), there is definitely an awareness of the potential borne by HR policies to motivate teachers for mobility and development (Runhaar 2008).

Integrated Personnel Management (IPM). The first development was that, in 2005, the Dutch Ministry of Education, Culture, and Science decided that every school management within secondary education nationwide needed to introduce a system of Integrated Personnel Management (IPM) (Kervezee 2006). Therefore, secondary schools are now obliged to have an integrated human resource management system in place. Although IPM is currently gaining more interest from schools, it is still far from common practice in secondary education (Runhaar 2008).

IPM combines four types of HR policy: (1) personnel management, for example, administration, planning, managing absenteeism; (2) organizational policy, for example, organizational structure, culture, employee participation; (3) the use of personnel instruments, for example, for recruitment, professional development, appraisals; and (4) competence management, for example, relating the development of teaching staff to organizational needs (SBO IPB 2005). These four aspects need to be integrated in three ways. First, vertical alignment between the goals of the 
school and the development of its teachers is needed. Second, there needs to be horizontal alignment among the four aspects of IPM, so that they reinforce rather than interfere with one another. And third, all those concerned (management as well as teaching staff) need to be involved in implementing IPM. Van Driel (2006) states that school management plays a critical role in schools' HR policies.

HR Policies Based on the SOAP Principle. The second development is that, since the mid-1990 s, Dutch schools have been granted more autonomy from the government (Seezink et al. 2010). As a result, some schools have decided to introduce innovative HR policies. A number of Dutch schools have recently been experimenting with an application of the so-called SOAP principle (Seezink et al. 2010; see also Van der Sanden 2004) in their HR policies. The focus of the SOAP principle is to establish stronger relationships among activities in the fields of Schooling of teachers, Organizational development of schools and teacher training institutes, Action- and development-oriented research, and Professional development of teachers.

Central to the SOAP approach is the formation of knowledge communities of researchers, student teachers, teacher educators, teachers, and employees of other work organizations (Engeström et al. 2004). Van der Sanden (2004) stresses the importance of these knowledge communities for initiating and organizing learning. Establishing stronger relationships among the SOAP associates provides them with opportunities to connect development at the individual level with that at the organization level. For example, teacher educators interacting with teachers on a frequent basis in order to create a new competence-based teaching program, which not only helps their individual learning but also brings about changes in what their institutions offer their respective clienteles.

\section{Study aim and research questions}

Both IPM and the SOAP approach attempt to influence the professional development of teachers' substantially. Continuing teacher development deemed necessary by many to prepare teachers for the new roles associated with the introduction of competence-based education. School management can, for instance, promote collaboration among teachers and encourage them to undertake specific professional development activities. It can promote new initiatives, rearrange work situations, and create facilities for teachers, so that the latter can define their personal development goals, share knowledge, and provide or receive coaching.

Schools are thus attempting to use their HR policies, government-enforced (IPM) as well as voluntary and experimental (SOAP), to make sure teachers engage in relevant professional development activities. What is unclear as yet, however, is exactly which role schools' HR policies play in the professional development of their teachers. The aim of this study, therefore, is to shed light on the professional development activities that PVSE teachers undertake to be able to play new roles in competence-based education programs and whether these activities differ among schools with various HR policies. The following research questions will be investigated:

1. Which professional development activities do PVSE teachers undertake?

2. To what extent are PVSE teachers able to identify elements of IPM and the SOAP approach in their schools' HR policies?

3. To what extent do the professional development activities of PVSE teachers differ among schools with different HR policies (as perceived by teachers)?

\section{Methods}

Design

We collected qualitative interview data from 30 PVSE teachers working in nine different schools, using semistructured questionnaires. The study was cross-sectional and explorative in nature, aiming at getting an insight into teachers' perceptions of professional development as well as of the HR policies that their schools had in place. Inductive as well as deductive approaches were used for the analysis, depending on the prior availability of relevant theoretical categories. To enable a test of whether there were any differences among schools with different HR policies, part of the interview data on teachers' professional development activities was quantified.

Sample

A total of 30 PVSE teachers from nine different schools participated in the study. Since the implementation of IPM was nationwide and obligatory for all Dutch secondary schools, 'participation in' IPM could not be used as a selection criterion. Six of the nine schools (hereafter referred to as 'SOAP schools') were selected because at the time they were actively participating in an experiment to introduce the SOAP principles into their HR policies. The other three schools ('non-SOAP schools') did not participate in a SOAP experiment but were selected for being involved in at least one innovative project aimed at implementing competence-based PVSE for pupils in their educational programs. This was done to match the general interest in educational innovations. 
Although, because of difficulties gaining access, the number of non-SOAP schools was only half the number of SOAP-schools, both types had 15 respondents. In the SOAP schools, all PVSE teachers approached for the interviews did participate. In the non-SOAP schools, teachers were invited to participate by the contact of the school, usually the principal or a board member. All teachers were free in their decision to participate or not. One teacher in a non-SOAP school decided not to participate in the interview study. Both SOAP and non-SOAP schools were located in the same province within the Netherlands in order to prevent regional differences.

The sample contained 17 men and 13 women. The average age was 43.7 years $(\mathrm{sd}=9.0)$, and the average teaching experience was 13.3 years $(s d=10.3)$. Subjects taught by the teachers included Dutch, Economics, Biology, Mathematics, English, and so forth. Among the 30 teachers, there was one vice principal, one coordinator, and three teachers with other management tasks (all besides their teaching duties). In the SOAP schools, nine men and six women participated, with an average age of 44.4 years $(\mathrm{sd}=8.52)$ and an average teaching experience of 14.4 years $(s d=10.19)$. In the non-SOAP schools, eight men and seven women participated, with an average age of 43.1 years $(\mathrm{sd}=9.48)$ and an average teaching experience of 12.3 years $(\mathrm{sd}=10.67)$.

\section{Instruments}

Data were gathered using semi-structured interviews. An interview protocol (available from the authors) was constructed consisting of a general introduction followed by questions about respondents' backgrounds (gender, age). The main part of the interview consisted of open-ended questions about the implementation of SOAP principles, teachers' professional development activities, school support for these activities, and implementation of IPM. As a starting point for the questions about teachers' professional development activities, the categories put forward by Kwakman (1999, 2003a) were used, that is, reading, experimenting, reflection, and collaboration. Questions about the SOAP principles were based on Seezink et al. (2010; see also Van der Sanden 2004). Questions about IPM were derived from SBO IPB (2005).

\section{Procedure}

Respondents were invited individually to participate in the study. They received a general outline of the main purpose of the study. Interviews took place from April through June of 2007, using secluded areas in the school buildings where the teachers were employed. There were two interviewers who were assigned randomly to the respondents. The interviews were recorded on a digital voice recorder with informed consent. After the analysis, the researchers performed member checks (Flick et al. 2004), meaning that respondents received an abstract of the interview summarizing all information gathered, classified into categories. All thirty respondents received an abstract of their own interview and were given the opportunity to react if they felt that the information or interpretation were incorrect. Relevant information collected during the member checks was used for further analysis.

\section{Analysis}

Data analysis was based on the constant comparative method (Miles and Huberman 1994). The interviews were fully transcribed, after which the coding procedure started. Core concepts derived from literature were coded into different subcategories. The analysis of the first research question regarding professional development activities (Kwakman 1999, 2003a) was mostly but not purely deductive in nature. Subcategories of emerging concepts were added if necessary. The analysis of the second and third research questions regarding perceived HR policies in schools was more inductive and explorative in nature. Key coding categories were based on SBO IPB (2005) for IPM and on Seezink et al. (2010; see also Van der Sanden 2004) for the SOAP approach.

Both interviewers coded the transcripts individually, based on the categories of core concepts. Almost all their scores matched, and any differences in coding scores were thoroughly evaluated. There was hardly any disagreement about which text fragment to place in which coding category; however, in a few instances, one researcher had scored a text fragment that the other researcher had omitted or vice versa. After discussing the differences, the transcripts were scored by both researchers individually a second time in order to accomplish a final version.

Data reduction was then accomplished by grouping codes into various categories. Finally, the information gained from performing these procedures was presented in a data matrix (available from the authors of this paper). The result was a total of 11 main categories subdivided into 62 subcategories. There were five main categories of professional development activities with 35 subcategories, one main category of IPM with 11 subcategories, and five main categories of the SOAP approach with 16 subcategories. The three research questions were answered by calculating the frequencies of the various professional development activities as well as the elements of HR policies perceived by teachers; their professional development activities were 
then compared between SOAP schools and non-SOAP schools and between schools with different perceived IPM policies.

\section{Results}

Teachers' professional development activities

The first research question focused on the professional development activities undertaken by PVSE teachers. The interviews showed that the teachers had rather different conceptions of professional development. Twelve teachers $(40 \%)$ could not give a specific answer when asked about their personal view of professional development or indicated that they did not know what the term intended when asked about their personal view of professional development. Some illustrative quotes of teachers:

"At first glance I would say that it is a hollow term." (respondent nr. 12).

"Well, I really think that is an invented idea." (respondent nr. 13)

"Professional development. Yes... What I think that means. Yes... Well, I don't know, really." (respondent nr. 15)

Eleven teachers (36\%) expressed a narrow view of professional development. Seven out of these eleven teachers $(23 \%)$ thought of professional development as one specific activity, mostly participating in courses or training sessions or maintaining their knowledge base. An illustrative quote:

"Professional development? Well, I think that it is following courses. Keeping up-to-date, that is new learning altogether." (respondent nr. 17)

The other four out of these eleven teachers (13\%) focused on continual learning and development without a further specification of this. An illustrative quote:

"That teachers learn, you know, that they develop themselves, that you become a better or different teacher." (respondent nr. 4)

Seven teachers $(23 \%)$ had a broader view of professional development; they viewed professional development as an integrated whole of multiple aspects. An illustrative quote:

"I understand that it is: how do you deal with the different classes, how do you deal with differences within pupils, so how to differentiate there, how do you plan your educational program, so also how do you make sure you use various didactical methods in concordance with the teaching subject, keeping it as up-to-date as possible that motivates pupils, that interests pupils I must say." (respondent nr. 1)

Subsequently, asked which activities they undertook in order to work on their professional development, teachers' answers could be divided into five main categories, four of which are derived from Kwakman (1999, 2003b): reading, experimenting, reflection, and collaboration. The category reading proposed by Kwakman was broadened to maintaining knowledge base, as teachers indicated undertaking a wider variety of activities besides reading. The category experimenting was broadened to applying and experimenting, as it includes, for example, teaching study skills to pupils and preparing classes. Finally, we added a new category 'activities indirectly related to teaching practice' (see Table 1 for an overview of results).

The most prevalent professional development activities within the first category maintaining knowledge base were participating in courses or training, followed by monitoring current educational affairs. Other, less prevalent activities were visiting (educational) publishers, using Internet as a resource, and reading newspapers.

In the second category applying and experimenting, most prominent were experimenting with teaching methods, undertaking new ways of teaching, and developing new teaching materials. Less prevalent activities were teaching study skills to pupils and preparing teaching practice.

The most prevalent activities within the third category reflecting were collegial consultation and evaluating one's own teaching practice. The term collegial consultation means that teachers discuss teaching practice together, particularly (problem) situations. Evaluating means the evaluation of school projects or specific lessons (by the teachers themselves). Less prevalent activities were receiving coaching, receiving feedback from pupils, and providing coaching for other teachers.

Within the fourth category collaborating, most prominent were participating in collaborative projects, exchanging or discussing ideas, participating in meetings, working within a core team or in a subject team, and, finally, collectively preparing teaching practice. Less prevalent were co-teaching and implementing innovations.

The most prevalent activities within the category activities indirectly related to teaching practice were providing pupil guidance and tasks not directly related to giving classes (e.g., creating a school paper, building a school's Internet site, and selecting schools for possible internships). Less prevalent in this category were activities such as management tasks and organizing extracurricular activities.

To control for within-subject recurring activities, we also looked at the numbers of teachers participating in the 
Table 1 Professional development activities undertaken by PVSE teachers in five main categories $(N=30)$

\begin{tabular}{|c|c|c|c|}
\hline Main category & Activity undertaken & Teachers $n(\%)$ & Activities $n(\%)$ \\
\hline \multirow[t]{9}{*}{ Maintaining knowledge base } & Participating in courses or training & $27(90 \%)$ & $75(69 \%)$ \\
\hline & Monitoring current educational affairs & $13(43 \%)$ & $16(15 \%)$ \\
\hline & Studying professional literature & $6(20 \%)$ & $9(8 \%)$ \\
\hline & Visiting of publishers & $3(10 \%)$ & $4(4 \%)$ \\
\hline & Using Internet as resource & $2(7 \%)$ & $2(2 \%)$ \\
\hline & Reading newspapers & $2(7 \%)$ & $2(2 \%)$ \\
\hline & Studying basic literature & $0(0 \%)$ & $0(0 \%)$ \\
\hline & Total number of activities in category & & $108(100 \%)$ \\
\hline & Total number of teachers in category & $28(93 \%)$ & \\
\hline \multirow[t]{8}{*}{ Applying and experimenting } & Experimenting with teaching methods & $25(83 \%)$ & $33(34 \%)$ \\
\hline & Undertaking new ways of teaching & $23(67 \%)$ & $33(34 \%)$ \\
\hline & Developing teaching materials & $16(53 \%)$ & $22(23 \%)$ \\
\hline & Teaching pupils study skills & $4(13 \%)$ & $5(5 \%)$ \\
\hline & Preparing classes & $4(13 \%)$ & $4(4 \%)$ \\
\hline & Constructing tests and evaluation & $0(0 \%)$ & $0(0 \%)$ \\
\hline & Total number of activities in category & & $97(100 \%)$ \\
\hline & Total number of teachers in category & $28(93 \%)$ & \\
\hline \multirow[t]{8}{*}{ Reflecting } & Collegial consulting & $18(60 \%)$ & $25(40 \%)$ \\
\hline & Evaluating & $13(43 \%)$ & $13(21 \%)$ \\
\hline & Supervising internships & $13(43 \%)$ & $13(21 \%)$ \\
\hline & Receive feedback of pupils & $6(20 \%)$ & $6(9 \%)$ \\
\hline & Receive coaching & $4(13 \%)$ & $4(6 \%)$ \\
\hline & Providing coaching & $2(7 \%)$ & $2(3 \%)$ \\
\hline & Total number of activities in category & & $63(100 \%)$ \\
\hline & Total number of teachers in category & $26(87 \%)$ & \\
\hline \multirow[t]{14}{*}{ Collaborating } & Participation in collaborative projects & $28(93 \%)$ & $34(26 \%)$ \\
\hline & Exchange or discussing ideas & $20(67 \%)$ & $24(18 \%)$ \\
\hline & Participating in meetings & $17(57 \%)$ & $23(18 \%)$ \\
\hline & Working within core/subject teams & $16(53 \%)$ & $18(14 \%)$ \\
\hline & Collectively preparing teaching practice & $9(30 \%)$ & $10(8 \%)$ \\
\hline & Co-teaching within one classroom & $7(23 \%)$ & $7(5 \%)$ \\
\hline & Implementing innovations & $6(20 \%)$ & $6(4 \%)$ \\
\hline & Providing assistance & $4(13 \%)$ & $4(3 \%)$ \\
\hline & Sharing teaching materials & $2(7 \%)$ & $2(2 \%)$ \\
\hline & Coordinating & $2(7 \%)$ & $2(2 \%)$ \\
\hline & Receiving assistance & $0(0 \%)$ & $0(0 \%)$ \\
\hline & Telling stories & $0(0 \%)$ & $0(0 \%)$ \\
\hline & Total number of activities in category: & & $130(100 \%)$ \\
\hline & Total number of teachers in category: & $30(100 \%)$ & \\
\hline \multirow[t]{6}{*}{ Activities indirectly related to teaching practice } & Providing pupil guidance & $11(37 \%)$ & $19(41 \%)$ \\
\hline & Tasks not related to giving classes & $8(26 \%)$ & $16(35 \%)$ \\
\hline & Management tasks & $6(20 \%)$ & $6(13 \%)$ \\
\hline & Extracurricular activities & $5(17 \%)$ & $5(11 \%)$ \\
\hline & Total number of activities in category & & $46(100 \%)$ \\
\hline & Total number of teachers in category & $19(63 \%)$ & \\
\hline
\end{tabular}

various (sub-) categories of professional development activities. For example, within the category maintaining knowledge base, 28 teachers were responsible for a total of
108 unique activities, whereas only 63 unique reflecting activities were conducted by 26 teachers. Results are summarized in Table 1. 
Table 2 Elements of IPM that teachers associated freely with IPM $(N=30)$

\begin{tabular}{lcc}
\hline IPM elements & Teachers $n(\%)$ & Expressions $n(\%)$ \\
\hline Professional development plan (PDP) & $18(60 \%)$ & $18(27 \%)$ \\
Appraisal meetings & $16(53 \%)$ & $16(24 \%)$ \\
Integrative approach & $10(33 \%)$ & $11(17 \%)$ \\
Involvement of teachers & $8(27 \%)$ & $8(13 \%)$ \\
Personnel officer & $5(17 \%)$ & $5(7 \%)$ \\
Promoting expertise & $3(10 \%)$ & $4(6 \%)$ \\
Recruitment & $2(7 \%)$ & $2(3 \%)$ \\
Health and safety regulations & $1(3 \%)$ & $1(1 \%)$ \\
Job appraisal & $1(3 \%)$ & $1(1 \%)$ \\
Career guidance & $1(3 \%)$ & $1(1 \%)$ \\
Total number of IPM elements & & $67(100 \%)$ \\
Total number of teachers & $25(83 \%)$ & \\
\hline
\end{tabular}

Schools' perceived human resource policies

The second research question focused on the extent to which PVSE teachers were able to identify elements of IPM and the SOAP approach in their schools' HR policies. First, we explored whether teachers were familiar with the term IPM. Ten teachers (33\%) did not know about it. Twenty teachers $(67 \%)$ who did know the term did not always know what it meant or how the school employed IPM. Their knowledge about IPM was often limited to it containing formative or summative appraisal meetings and drawing up a professional development plan (PDP). Table 2 summarizes teachers' free expressions related to IPM.

Although twenty teachers claimed to know the term IPM, twenty-five teachers actually mentioned elements of IPM in response to the open-ended questions. Apparently, teachers did not always recognize elements of IPM as such. Eighteen teachers experienced professional development plans (PDPs) as being part of IPM, with the implementation of PDPs varying between just putting a plan on paper and undertaking a program over several years with an assigned coach to ensure progress. Sixteen teachers mentioned formative or summative appraisal meetings, although they often said this did not happen on a regular basis, usually only once or twice. The involvement of teachers in implementing IPM was limited (27\%). Often, this task belongs to team leaders, subject group managers, board members, and management teams.

Subsequently, it was investigated to what extent teachers identified the four elements of the SOAP principle: Schooling of teachers, Organizational development of schools and teacher training institutes, Action- and development-based research, and Professional development of teachers. Since an integrative approach to these four elements should be part and parcel of the SOAP principle, this was also investigated in the analysis. Table 3 shows teachers' perceptions of the extent to which elements of the SOAP principle were present in their schools' policies. Most present in school policies as perceived by teachers were the elements of professional development and organizational development, with less emphasis on research and far less attention being given to schooling of teachers.

Data about the integrative approach to all elements of the SOAP principle are not in Table 3; however, after talking about each of the four elements separately, nine teachers $(30 \%)$ when asked indicated that all four aspects of SOAP were present, fourteen teachers $(47 \%)$ mentioned three aspects, six teachers (20\%) mentioned two aspects, and one teacher $(3 \%)$ mentioned only one aspect. Ten teachers $(33 \%)$ perceived an integrative approach to some extent, but mostly involving only two out of four aspects. No teachers perceived an integrative approach involving all four SOAP elements.

Table 3 Teachers' perceptions of elements of SOAP present in their schools' HR Policies $(\mathrm{N}=30)$

\begin{tabular}{llll}
\hline Perceived elements of SOAP & SOAP schools $n(\%)$ & Non-SOAP schools $n(\%)$ & Total $n(\%)$ \\
\hline Schooling of teachers & $8(40 \%)$ & $12(60 \%)$ & $20(100 \%)$ \\
Organizational development & $33(43 \%)$ & $44(57 \%)$ & $77(100 \%)$ \\
Action/development-based research & $11(35 \%)$ & $20(65 \%)$ & $31(100 \%)$ \\
Professional development of teachers & $19(49 \%)$ & $20(51 \%)$ & $39(100 \%)$ \\
\hline
\end{tabular}

Note: A total of 30 respondents were interviewed: 15 from SOAP schools and 15 from non-SOAP schools. The total number of perceived elements differed per category; therefore, this number is provided in the right-hand column 
Different professional development activities among schools with different HR policies

The third research question focused on the extent to which the professional development activities of PVSE teachers differed among schools with different perceived HR policies. Regarding the perception of IPM, on the basis of our interviews, we could identify three groups: ten teachers had never heard of IPM (and, therefore, cannot experience an integrated approach to IPM), ten teachers were familiar with IPM but did not experience an integrative approach, and, finally, ten teachers were familiar with IPM and did experience an integrative approach.

Main results with regard to the professional development activities undertaken are that teachers not familiar with IPM scored lowest of the three groups on applying and experimenting and activities indirectly related to teaching. Teachers who were familiar with IPM but did not experience an integrative approach scored highest in collaborating, maintaining knowledge base and applying and experimenting; however, reflecting scored lowest. Teachers familiar with an integrated approach to IPM scored highest of the three groups on reflecting and activities indirectly related with teaching but lowest on collaborating and maintaining knowledge base.

In order to determine whether the differences among the three groups were statistically significant, we performed a Pearson's $\chi^{2}$ test for the numbers of activities, which revealed a significant difference on maintaining knowledge base $\left(\chi_{(2)}^{2}=8.72, p<0.05\right)$. All other categories did not reveal any significant differences $\left(\chi_{(2)}^{2}\right.$ varied between 0.57 and 2.67). The results are summarized in Table 4. We also conducted Pearson's $\chi^{2}$ tests for the numbers of teachers as well as for the 'activity to teacher ratios'; however, no significant differences emerged from these analyses.

Regarding the differences between SOAP schools and non-SOAP schools, Table 5 presents the professional development activities of PVSE teachers at the main category level (results at the activity level can be obtained from the authors). Some differences are apparent between the two school types; however, these differences in professional development activities are only slight. The category reflecting shows the clearest differences, in that these activities were much more frequent in non-SOAP schools compared to SOAP schools. There are only marginal differences in the categories maintaining knowledge base, collaboration, and applying and experimenting. Regarding activities indirectly related to teaching practice, more teachers within SOAP schools claimed to pursue these compared to teachers in non-SOAP schools; however, the number of activities undertaken is roughly similar. Pearson's $\chi^{2}$ tests for activities, teachers, and 'activity to teacher ratios' did not reveal any significant differences among the two groups.

\section{Conclusions and discussion}

This study was conducted among Dutch PVSE teachers in order to shed light on their professional development activities and to explore whether these activities differ among schools with different perceived HR policies. As for the first research question, regarding teachers' views of professional development, almost half of the sample could not give any specific answer when asked to describe their views. The professional development activities that they undertook could be categorized in collaborating, closely followed in prevalence by maintaining knowledge base, and applying and experimenting, then reflecting and finally activities indirectly related to teaching practice.

The second research question focused on the extent to which PVSE teachers were able to identify elements of IPM and SOAP within their schools' HR policies. Although schools are obliged by the Dutch government to have Integrated Personnel Management as part of their HR policies, $33 \%$ of the teachers were not familiar with this

Table 4 Number of professional development activities undertaken by three groups of teachers $(N=30)$

\begin{tabular}{lllll}
\hline Main categories of activities & $\begin{array}{l}\text { Teachers not familiar with } \\
\text { IPM }(n=10)\end{array}$ & \begin{tabular}{l} 
Teachers familiar with IPM $(n=20)$ \\
\cline { 3 - 4 }
\end{tabular} & $\begin{array}{l}\text { No integrative approach to IPM } \\
\text { perceived }(n=10)\end{array}$ & $\begin{array}{l}\text { Integrative approach to IPM } \\
\text { perceived }(n=10)\end{array}$ \\
\hline Collaborating & $42(32 \%)$ & $51(39 \%)$ & $37(28 \%)$ & $130(100 \%)$ \\
Maintaining knowledge base & $37(34 \%)$ & $48(44 \%)$ & $30(21 \%)$ & $108(100 \%)$ \\
Applying and experimenting & $28(29 \%)$ & $39(40 \%)$ & $27(43 \%)$ & $67(100 \%)$ \\
Reflecting & $19(30 \%)$ & $17(27 \%)$ & $17(37 \%)$ & $46(100 \%)$ \\
$\begin{array}{c}\text { Activities indirectly related to } \\
\text { teaching practice }\end{array}$ & $13(28 \%)$ & $16(35 \%)$ & &
\end{tabular}

Note: A total of 30 respondents were interviewed: 10 of them were familiar with IPM, 10 were familiar with IPM but did not see an integrative approach, and 10 were familiar with IPM and perceived an integrative approach. The total number of activities undertaken differed per category; therefore, this number is provided in the right-hand column 
Table 5 Differences between SOAP/non-SOAP schools in the number of professional development activities undertaken by teachers, per main category $(N=30)$

\begin{tabular}{lllll}
\hline Main category of activities undertaken & SOAP schools & & \multicolumn{2}{l}{ Non-SOAP schools } \\
\cline { 2 - 3 } & Teachers $n(\%)$ & Activities $n(\%)$ & Teachers $n(\%)$ & Activities $n(\%)$ \\
\hline Collaborating $(n=130)$ & $15(100 \%)$ & $59(45 \%)$ & $15(100 \%)$ & $71(55 \%)$ \\
Maintaining knowledge base $(n=108)$ & $15(100 \%)$ & $59(55 \%)$ & $13(87 \%)$ & $49(45 \%)$ \\
Applying and experimenting $(n=97)$ & $15(100 \%)$ & $49(51 \%)$ & $13(87 \%)$ & $48(49 \%)$ \\
Reflecting $(n=63)$ & $11(73 \%)$ & $27(43 \%)$ & $14(93 \%)$ & $36(57 \%)$ \\
Activities indirectly related to teaching practice $(n=46)$ & $11(73 \%)$ & $24(52 \%)$ & $7(47 \%)$ & $22(48 \%)$ \\
\hline
\end{tabular}

Note: A total of 30 respondents were interviewed: 15 from SOAP schools and 15 from non-SOAP schools; the total numbers of activities undertaken are provided per main category in the left-hand column

term. Teachers perceived fewer elements of IPM and SOAP, and less integration within both of these HR policies, than might be expected given that IPM is now compulsory and SOAP is a voluntary effort on the part of their schools. Also, very few teachers $(27 \%)$ were involved in implementing these HR policies in their schools.

The third research question investigated whether there were any differences in teachers' professional development activities among schools with different perceived HR policies. Not many differences emerged from the analyses. The level of familiarity of teachers with IPM did make a difference to the professional development category maintaining knowledge base. The differences between SOAP and non-SOAP schools were only marginal.

\section{Theoretical implications}

Initially, we were not completely sure whether the professional development categories proposed by Kwakman $(1999,2003 a)$ were appropriate because of the diversity and unique characteristics of the PVSE setting. Analyzing the activities conducted by PVSE teachers showed, however, that the clusters formulated by Kwakman were meaningful, although some categories were renamed and a fifth category was added (i.e., activities indirectly related to teaching practice). One may argue that the latter activities do not contribute directly to the professional development of teachers, although teachers view them as a part of it. These activities differ greatly in nature but often require both specialized skills and an invitation by colleagues or school board members, which makes these stand out from the other categories. Teachers with an inwardfocused motivation would seem more likely to get involved in these kinds of activities, as they pertain mostly to school-bound tasks (Blau et al. 2008). Further research is needed to investigate the relevance and prevalence of our additional fifth category.

Some researchers (Beijaard and Verloop 1996; Oosterheert 2001; Van Velzen 2002) have argued that teachers' practical theories or individual action theories play a crucial role in their teaching. It can be expected that these theories play a role in teachers' professional development activities as well (Poell and Van der Krogt 2008). Teachers holding more elaborate and explicit professional development theories are more aware of their specific fields of expertise as well as their knowledge gaps. There could thus be a relationship between the number and diversity of professional development activities mentioned by teachers, on the one hand, and the extent to which their practical theories or individual action theories are crystallized, on the other hand (Seezink et al. 2010). Here, again, further research is necessary.

With increasing attention being paid to HR policies within educational institutions, various HR instruments also have made their entry into schools. Many of these instruments focus on integrating organizational development with continuing teacher development. A few empirical studies so far, however, have addressed the issue of how teachers perceive their schools' HR policies and instruments. The present study shows that neither government obligation nor voluntary school participation is sufficient in themselves for HR policies to become visible and meaningful to many teachers, let alone be integrated into their daily teaching and learning practices. One might even, in view of this, ask to what extent IPM takes into account enough the needs and interests of teachers (as opposed to the needs and interests of school managers and HR officers) in professional and organizational development. The SOAP approach, by contrast, seems to be more focused on teachers' needs and interests, which makes the lack of differences found between SOAP and non-SOAP schools all the more surprising. We will return to this issue later on in this discussion section.

The Dutch educational system has a rich, but also rather problematic, history of implementing educational reforms (e.g., the "independent-study centre" and "basic (secondary school) curriculum" reforms, or in Dutch: "studiehuis" and "basisvorming") that were not communicated very 
well to the field. A critical evaluation of these educational reforms by the Dijsselbloem committee (initiated by the Dutch government) concluded that the government intruded on pedagogical and didactical grounds, took too little time for implementing the reforms, and overburdened education with new ambitions (Dijsselbloem 2008). Such badly prepared educational reforms frustrate teachers, who may become less ready to change and more critical toward educational reforms as a result. Since our study showed that a few teachers are involved in implementing HR policies, in the context of ill-conceived educational reforms described above, teachers can become even more focused on daily practice and less on organizational, professional, or political developments. This argument is in line with Grieves and Hanafin (2005), who concluded that HR policies within schools in the United Kingdom seem to be undervalued and left to untrained personnel. They argued, and rightly so, that IPM should be managed by HR professionals in order to avoid ambiguity and overly pragmatic decisions taken by line managers.

At the outset of our study, we considered it plausible that teachers operating within an integrated SOAP context would conduct more activities and also engage in a broader range of activities compared to teachers working in a nonSOAP environment. The underlying assumption was that the integrated SOAP context is more susceptible to innovations, so there would be more attention to professional development opportunities. Surprisingly, however, teachers' professional development activities were found to be roughly similar for the integrated SOAP context and the non-SOAP context. Moreover, teachers did not experience an integration of the four SOAP aspects within their schools' HR policies. One possible explanation for these surprising findings may be that the non-SOAP schools were selected for being involved in at least one innovative project aimed at implementing competence-based PVSE for pupils in their educational programs (in order to match the sample schools' general interest in educational innovations). There were clear indications (see Table 3) that the non-SOAP schools also displayed the SOAP principles, even more so than the SOAP schools, although they did not use this label within their HR policies. This is in line with theoretical arguments from the learning organization literature that it does not really matter how organizations strive toward becoming learning organizations as long as they do so deliberately, continually, and consciously (e.g., De Laat and Simons 2002). A recommendation for further research is, therefore, not to identify schools on the basis of their self-proclaimed SOAP label, but to investigate the degree to which they exhibit the actual characteristics of SOAP.

Another possible explanation for the similar results in SOAP and non-SOAP contexts is that the SOAP schools decided to participate in the SOAP experiments in the first place because they realized that they were lagging behind in the development of HR practices, compared to other schools engaged in competence-based innovations. In that case, getting involved in SOAP would have been an attempt to compensate, which would be in line with the finding that non-SOAP schools displayed more instances of the SOAP principles than did SOAP schools (see Table 3). Further research into this issue is needed.

\section{Study limitations and practical implications}

The research design used for this study has several limitations. Only a relatively small number of teachers $(n=30)$ participated in the study; therefore, the results cannot be generalized to all PVSE teachers unquestioningly. An attempt was made, however, to make the SOAP and non-SOAP research contexts comparable on several criteria (e.g., male/female ratio, age, experience, the selected schools needed to be involved in innovative projects, and so forth).

Another limitation is the voluntary participation of teachers in the interviews. It is possible that teachers willing to be interviewed have different characteristics than those teachers who did not want to participate. For example, the former may be more inclined to engage in professional development than the latter. Having relatively open interviews with teachers about their professional development activities also holds the pitfall that they do not express all activities they undertake.

Finally, we want to address some practical implications for PVSE teachers as well as PVSE schools. As educational institutions, schools have the responsibility to provide their teachers with opportunities for professional development. The fact that almost half of all teachers could not give a specific answer when asked about their view of professional development is at least an indication that this topic is not very high on their agenda nor on the agenda of their schools. Teachers should be more aware of the benefits of professional development, and school organizations should be clearer about the need for professional development. IPM is not intended to be solely a tool of management although some might think it is. If, however, teachers leave IPM to be handled by school managers, they might miss out on opportunities to use IPM for their own needs and interests. Schools need to go beyond the rather bureaucratic approach of IPM to engage their teachers in a collaborative approach to professional and career development that is also in the interests of individual teachers. They should involve teachers in shaping HR policies that do justice to the purposes and methods of professional and career development subscribed to by teachers. This could have an impact on the ways in which teachers think of professional 
and career development, their motivation to participate in development activities, and the actual learning that occurs in doing so (Poell and Van der Krogt 2008).

Furthermore, teachers' perceptions of their schools' HR policies (e.g., the integration of SOAP elements) seemed to differ from the HR policies intended by the schools. It is the responsibility of school management to make their HR policies clear to the teachers. If schools have highly transparent HR policies, teachers will be more aware of their professional development opportunities. That in turn lowers the threshold for those teachers who want to invest in their professional development, because they are aware of the steps they have to take. Maybe teachers are apprehensive about undertaking activities that cost money and time if they do not experience support from school management. Clearly communicated and transparent HR policies in schools can make a difference in this respect.

Open Access This article is distributed under the terms of the Creative Commons Attribution Noncommercial License which permits any noncommercial use, distribution, and reproduction in any medium, provided the original author(s) and source are credited.

\section{References}

Atay, D. (2008). Teacher research for professional development. ELT Journal, 62, 139-147.

Beijaard, D., \& Verloop, N. (1996). Assessing teachers' practical knowledge. Studies in Educational Evaluation, 22, 275-286.

Bergen, T., \& Van Veen, K. (2004). Het leren van leraren in een context van onderwijsvernieuwingen: Waarom is het zo moeilijk? [Teacher learning in a context of educational innovations: Why is it so difficult?]. VELON Tijdschrift voor Lerarenopleiders, 25, 29-39.

Biemans, H., Nieuwenhuis, L., Poell, R. F., Mulder, M., \& Wesselink, R. (2004). Competence-based VET in the Netherlands: Background and pitfalls. Journal of Vocational Education \& Training, 56, 523-538.

Blau, G., Andersson, L., Davis, K., Daymont, T., Hochner, A., Koziara, K., et al. (2008). The relation between employee organizational and professional development activities. Journal of Vocational Behavior, 72, 123-142.

Clandinin, D. J. (2008). Creating learning spaces for teachers and teacher educators. Teachers and Teaching: Theory and Practice, 14, 385-389.

De Bruijn, E. (2004). Beroepsonderwijs in ontwikkeling [Vocational education in development]. Kluwer, Netherlands: Alphen aan den Rijn.

De Bruijn, E., Overmaat, M., Glaude, M., Heemskerk, I., Leeman, Y., Roeleveld, J., et al. (2005). Krachtige leeromgevingen in het middelbaar beroepsonderwijs: Vormgeving en effecten [Powerful learning environments in secondary vocational education: Design and effects]. Pedagogische Studien, 82, 77-95.

De Laat, M. F., \& Simons, P. R. J. (2002). Collective learning: Theoretical perspectives and ways to support networked learning. European Journal for Vocational Training, 27, 13-24.

Dijsselbloem, J. (2008). Parlementair onderzoek onderwijsvernieuwingen [Parliamentary Inquiry Educational Innovations].
Accessed 2 April 2009 from http://www.tweedekamer.nl/ images/kst113842.8s_tcm118-149847.PDF.

Engeström, Y., Toiviainen, H., Pasanen, A., \& Haavisto, V. (2004, 6-11 August). Collaborative concept formation at work. Paper presented at the Academy of Management Meeting, New Orleans, USA.

Flick, U., Von Kardoff, E., \& Steinke, I. (2004). A companion to qualitative research. London, UK: Sage.

Grieves, J., \& Hanafin, P. (2005). Human resource management: The Achilles heel of school governance. Employee Relations, 27, 20-46.

Kallenberg, A. J. (2004). Tussen opleiden en professionele ontwikkeling: Leren (en) organiseren van nieuwe arrangementen [Between training and professional development: Learning and organizing new arrangements]. Leiden, Netherlands: Hogeschool Leiden.

Kervezee, C. (2006). De staat van het onderwijs: Onderwijsverslag 2004/2005 [The state of education: Educational report 2004/ 2005]. Accessed 16 December 2008 from http://www.staat vanhetonderwijs.nl/pdf/onderwijsverslag.pdf.

Kwakman, K. (1999). Leren van docenten tijdens de beroepsloopbaan: Studies naar professionaliteit op de werkplek in het voortgezet onderwijs [Teacher learning during the career: Studies into professionalism at the workplace in secondary education]. PhD dissertation, Katholieke Universiteit Nijmegen, Netherlands.

Kwakman, K. (2003a). Factors affecting teachers' participation in professional learning activities. Teaching and Teacher Education, 19, 149-170.

Kwakman, K. (2003b). Leren van professionals tijdens de beroepsuitoefening [Learning of professionals during the career]. In $\mathrm{J}$. W. M. Kessels \& R. F. Poell (Eds.), Human resource development: Organiseren van het leren (pp. 229-242). Kluwer, Netherlands: Alphen aan den Rijn.

Lohman, M. C. (2006). Factors influencing teachers' engagement in informal learning activities. Journal of Workplace Learning, 18, 141-156.

Miles, M. B., \& Huberman, A. M. (1994). A qualitative data analysis: An expanded source book (2nd ed.). Thousand Oaks, CA: SAGE Publications.

Mulder, M. (2002). Competentieontwikkeling in organisaties: Perspectieven en praktijk [Competence development in organizations: Perspectives and practices]. The Hague, Netherlands: Elsevier.

Oosterheert, I. E. (2001). How student teachers learn: A psychological perspective on knowledge construction in learning to teach. $\mathrm{PhD}$ dissertation, Rijksuniversiteit Groningen, Netherlands.

Poell, R. F., \& Van der Krogt, F. J. (2008). The role of social networks in managing organizational talent, knowledge and employee learning. In V. Vaiman \& C. Vance (Eds.), Smart talent management (pp. 93-118). London: Edward Elgar.

Runhaar, P. R. (2008). Promoting teachers' professional development. PhD dissertation, University of Twente, Netherlands.

SBO IPB. (2005). Handboek integraal personeelsbeleid voortgezet onderwijs [Handbook Integrated Personnel Management for secondary education]. The Hague, Netherlands: SBO IPB.

Scribner, J. P., Smylie, M. A., \& Mosley, H. L. (2008, March 24-28). District workforce development and instructional capacity: A strategic perspective. Paper presented at the annual AERA conference, New York, NY.

Seezink, A., \& Poell, R. F. (2010). Continuing professional development needs of teachers in schools for competence-based vocational education: A case study from the Netherlands. Journal of European Industrial Training, 34(5), 455-474.

Seezink, A., Poell, R. F., \& Kirschner, P. A. (2009). Teachers' individual action theories about competence based education: 
The value of the cognitive apprenticeship model. Journal of Vocational Education and Training, 61(2), 203-215.

Seezink, A., Poell, R. F., \& Kirschner, P. A. (2010). SOAP in practice: Learning outcomes of a cross-institutional innovation project conducted by teachers, student teachers, and teacher educators. European Journal of Teacher Education, 33(3), 229-242.

Tomlinson, P. (1995). Can competence profiling work for effective teacher preparation? Oxford Review of Education, 21, 179-194.

Van der Sanden, J. M. M. (2004). Ergens goed in worden: Naar leerzame loopbanen in het beroepsonderwijs [Becoming good at something: Towards rich learning careers in vocational education]. Eindhoven, Netherlands: Fontys Hogeschool.

Van Driel, L. (2006). Professionalisering in school: Een studie naar verbetering van het pedagogisch-didactisch handelen [Professionalization in the school: A study into the improvement of pedagogical-didactical practice]. $\mathrm{PhD}$ dissertation, Universiteit Utrecht, Netherlands.

Van Velzen, J. H. (2002). Instruction and self-regulated learning: Promoting students' (self) reflective thinking. $\mathrm{PhD}$ dissertation, Universiteit Leiden, Netherlands.

Vermunt, J. D., \& Verschaffel, L. (2000). Process-oriented teaching. In P. R. J. Simons, J. L. Van der Linden, \& T. M. Duffy (Eds.), New learning (pp. 209-225). Dordrecht, Netherlands: Kluwer.

Watkins, J. (1999). UK professional associations and continuing professional development: A new direction? International Journal of Lifelong Education, 18, 61-75.

Weigel, T., Mulder, M., \& Collins, K. (2007). The concept of competence in the development of vocational education and training in selected EU member states. Journal of Vocational Education \& Training, 59, 53-66. 